Reisinger $\cdot$ Rechtsinformatik 



\section{Leo Reisinger}

\section{Rechtsinformatik}


Dr. Dr. Leo Reisinger,

Universitäts-Dozent am Institut für Statistik der Universität Wien

CIP-Kurztitelaufnahme der Deutschen Bibliothek

Reisinger, Leo

Rechtsinformatik. - 1. Aufl. - Berlin, New York:

de Gruyter, 1977.

ISBN 3-11-004582-6

(C) Copyright 1977 by Walter de Gruyter \& Co., vormals G. J. Göschen'sche Verlagshandlung, J. Guttentag, Verlagsbuchhandlung Georg Reimer, Karl J. Trübner, Veit \& Comp., Berlin 30. Alle Rechte, insbesondere das Recht der Vervielfältigung und Verbreitung sowie der Übersetzung, vorbehalten. Kein Teil des Werkes darf in irgendeiner Form (durch Photokopie, Mikrofilm oder ein anderes Verfahren) ohne schriftliche Genehmigung des Verlages reproduziert oder unter Verwendung elek tronischer Systeme verarbeitet, vervielfältigt oder verbreitet werden. - Satz: IBM-Composer, Fotosatz Prill, Berlin. - Druck: Color Druck, Berlin. Bindearbeiten: Dieter Mikolai, Berlin. - Printed in Germany. 